\title{
Morfologia da laringe de cutia (Dasyprocta sp.) ${ }^{1}$
}

\author{
Andrezza B.S. Silva ${ }^{2 *}$, Thais M.V. Santos ${ }^{2}$, Maria Acelina M. Carvalho², Paulo S.L. \\ Guerra $^{2}$, Marcia S. Rizzo ${ }^{2}$, Waldilleny R. Araújo ${ }^{2}$, Cristiane B.B. Torres ${ }^{2}$ \\ e Airton M. Conde Junior ${ }^{2}$
}

\begin{abstract}
Silva A.B.S., Santos T.M.V., Carvalho M.A.M., Guerra P.S.L. Rizzo M.S., Araújo W.R., Torres C.B.B. \& Conde-Junior A.M. 2014. [Morphology of the larynx of agouti (Dasyprocta sp.).] Morfologia da laringe da cutia (Dasyprocta sp.). Pesquisa Veterinária Brasileira 34(6):593-598. Setor de Histologia e Embriologia, Universidade Federal do Piaui, Campus Universitário Ministro Petrônio Portella, Bairro Ininga, Teresina, PI 64049-550, Brazil. E-mail: andrezzab1@hotmail.com

The agouti (Dasyprocta sp.) is a wild rodent with worldwide distribution. Besides its ecological role, agouti is used as a model in animal experimentation. Studies on the morphology of agouti are important because they can be an alternative for the study of various pathological processes and contribute to the preservation of the species. The larynx, located between the pharynx and trachea, is involved in the functions of breathing, swallowing and speech. This study aimed to perform a macroscopic and microscopic morphology of the larynx of agouti. To this end, we used fifteen agoutis belonging to the Centre of Agricultural Sciences, Federal University of Piauí, and from the Center for Study and Preservation of Wild Animals with license of IBAMA (No. 02/08-618, CTF No. 474064). All animals were identified according to their gender, the larynx was dissected and cartilaginous fragments were sent for routine histology and stained with hematoxylin-eosin. The slides obtained were viewed in light microscopy and photo documented. The larynx of agouti has five cartilages, without the cuneiform cartilage but presence of the thyroid cartilage notch. The epithelial tissue of the larynx varies from stratified squamous epithelium to keratinized and non-keratinized ciliated caliciforme cells.
\end{abstract}

INDEX TERMS: Agouti, Dasyprocta sp., larynx, wild rodents, morphology.

RESUMO.- A cutia (Dasyprocta sp.) é um roedor silvestre com distribuição mundial. Atualmente, além de importante papel ecológico que exerce, está sendo utilizada como modelo em experimento animal. Estudos sobre a morfologia destes animais são importantes porque podem ser uma alternativa para o estudo de diversos processos patológicos, além de contribuirem para a preservação da espécie. A laringe é um órgão localizado entre a faringe e a traqueia, no qual está envolvido nas funções de respiração, deglutição e fonação. 0 presente estudo propôs realizar uma descrição morfológica macroscópica e microscópica da laringe

\footnotetext{
${ }^{1}$ Recebido em 21 de agosto de 2013.

Aceito para publicação em 27 de março de 2014.

${ }^{2}$ Departamento de Morfologia, Universidade Federal do Piaui (UFPI), Campus Ministro Petrônio Portela, Av. Nossa Senhora de Fátima, Bairro Ininga, PI 64049-550, Brasil. *Autor para correspondência: andrezzab1@ hotmail.com
}

da cutia. Para tanto, foram utilizadas quinze cutias pertencentes ao Centro de Ciências Agrárias da Universidade Federal do Piauí e provenientes do Núcleo de Estudos e Preservação de Animais Silvestres com licença do IBAMA (№ 02/08-618, CTF № 474064). Todos os animais foram identificados, promovida a sexagem e, posteriormente, a laringe acessada e dissecada sendo os fragmentos cartilagíneos encaminhados para rotina histológica e corados pelo método de hematoxilina-eosina. As lâminas obtidas foram visualizadas em microscopia óptica de luz e foto documentadas. A laringe da cutia apresenta cinco cartilagens, com ausência da cartilagem cuneiforme e presença da incisura caudal na cartilagem tireoide. 0 tecido epitelial da laringe varia de epitélio estratificado pavimentoso queratinizado à não queratinizado e ciliado com células caliciformes.

TERMOS DE INDEXAÇÃO: Cutia, Dasyprocta sp., laringe, roedores silvestres, morfologia. 


\section{INTRODUÇÃO}

A cutia (Dasyprocta sp.) é o terceiro maior roedor brasileiro, pertencente à família Dasyproctidae, pesando de 1,5 a 2,8 kg (Martins et al. 2010, Pires \& Galetti 2012). São animais terrestres de hábitos diurnos, extremamente ágeis, possuindo membros finos em relação ao tronco o que os torna excelentes corredores. Apresentam pelagem áspera, uniforme na cor ocre, cujos tons variam do alaranjado ao avermelhado (Hosken 2001, Arruda \& Julião 2006).

Os roedores, em geral, por apresentarem aspectos característicos, tais como tamanho adequado e baixo custo de manutenção, são considerados animais experimentais (Martins et al. 2010). Atualmente, as cutias vêm passando por um processo de preservação natural, visto que suas espécies sofrem com a caça predatória e estão entre os animais vulneráveis ou que corre um alto risco de extinção (Marques et al. 2002). Estudos envolvendo esta espécie demonstram que a mesma é considerada como fonte alimentar de proteína além de dispersores de sementes para manutenção do equilíbrio dos ecossistemas.

Este fato justifica o estudo de diferentes aspectos destes animais, visto que o conhecimento da anatomia e da fisiologia dos órgãos da cutia aprimorou-se com o tempo. Por meio de pesquisas na laringe dos quatis (Nasua nasua), Oliveira et al.. (2012) concluiu que trata-se de um órgão localizado entre a faringe e a traqueia e envolvido nas funções de respiração, deglutição e fonação, semelhante ao observado nas cutias (Philippi 2005).

Um dos obstáculos encontrados na clínica animal de roedores é a dificuldade de implantar uma anestesia inalatória eficiente. Visto que, o posicionamento caudal da laringe associado à entrada restrita da cavidade do órgão não facilitam o acesso da sonda endotraqueal nesses animais. Durante um longo período, o uso de máscara facial para intubá-los vem sendo uma alternativa à anestesia inalatória. Porém, o tempo mostrou a ocorrência de efeitos adversos $\mathrm{cm}$ esta técnica. Atualmente, a tecnologia aliada a conhecimentos específicos do órgão possibilitaram pesquisadores a implantarem a máscara laríngea, utensílio indispensável na clínica de roedores e que direciona a importância desses estudos também à clínica médica (Diniz 2007).

Com relação à laringe de cutias, trabalhos sobre a morfologia da laringe nestes roedores são ainda escassos. Desta feita, este estudo propôs realizar uma descrição morfológica macroscópica e microscópica das cartilagens da laringe de cutia (Dasyprocta sp.) para que se possa, através dos dados obtidos promover um estudo comparativo com outras espécies silvestres e domésticas.

\section{MATERIAL E MÉTODOS}

Este estudo foi realizado na Universidade Federal do Piauí (UFPI), no Laboratório de Anatomia Animal do Centro de Ciências Agrárias (CCA) e no Laboratório de Histologia e Embriologia do Departamento de Morfologia do Centro de Ciências da Saúde (CCS).

Foram utilizadas quinze cutias macho (Dasyprocta sp.) pertencentes ao Centro de Ciências Agrárias da Universidade Federal do Piauí e provenientes do Núcleo de Estudos e Preservação de Animais Silvestres com licença do IBAMA (№ 02/08-618, CTF №
474064). Os animais foram eutanasiados eticamente, conforme orientações do Conselho Federal de Medicina Veterinária.

Estudo macroscópico. Dos quinze animais utilizados, doze cutias foram fixadas em formaldeído a $10 \%$ tamponado, armazenadas em depósito devidamente identificado e estocadas no Laboratório de Anatomia Animal. Estes animais foram identificados e foi realizada a dissecação dos componentes do sistema respiratório iniciando com uma incisão ventral da região cervical. A laringe foi identificada e dissecada com o propósito de evidenciar os constituintes anatômicos deste órgão. Em seguida, efetuou-se a dissecação e identificação das cartilagens que formam esse órgão. Foram realizadas fotografias digitais das estruturas anatômicas com câmera fotográfica digital da marca Sony ${ }^{\circledR}$, modelo DSC 100, para documentalização dos resultados.

Estudo microscópico. Realizou-se a coleta da laringe em três cutias imediatamente após a eutanásia. 0 órgão extraído foi encaminhado para lavagem em água a $40^{\circ} \mathrm{C}$ e seccionado medialmente para obtenção de duas hemilaringes. Os fragmentos foram fixados em formaldeído tamponado a $10 \%$ e mantidos por 24 horas antes de serem processados em rotina histológica para coloração por hematoxilina e eosina. As lâminas com os cortes histológicos da laringe foram analisadas em microscópico de luz em objetivas de aumentos 10x e 40x. Realizadas fotomicrografias digitais dos órgãos, evidenciando tecidos e cartilagens.

\section{RESULTADOS}

A laringe da cutia (Dasyprocta sp.) está situada acima da orofaringe onde possui acesso direto à nasofaringe formando uma ponte que liga a faringe à porção posterior do sistema respiratório (Fig.1). 0 órgão localiza-se na porção caudal da região cervical devido à extensão da língua nesses animais, ficando apenas $20 \%$ do comprimento total desta na cavidade oral (Fig.2A). Este fato dificulta a inserção de uma sonda inalatória, além disso, a abertura do órgão restrita também contribui com esta situação.

A laringe na cutia apresenta três cartilagens simples: cricóide, tireóide e epiglote (Fig.2B-D); e duas pares: aritenóide e corniculada.

A cricóide, a mais caudal das cartilagens, situa-se rostralmente ao primeiro anel cartilaginoso traqueal, tem a forma anelar e apresenta uma larga placa dorsal quadrilá-

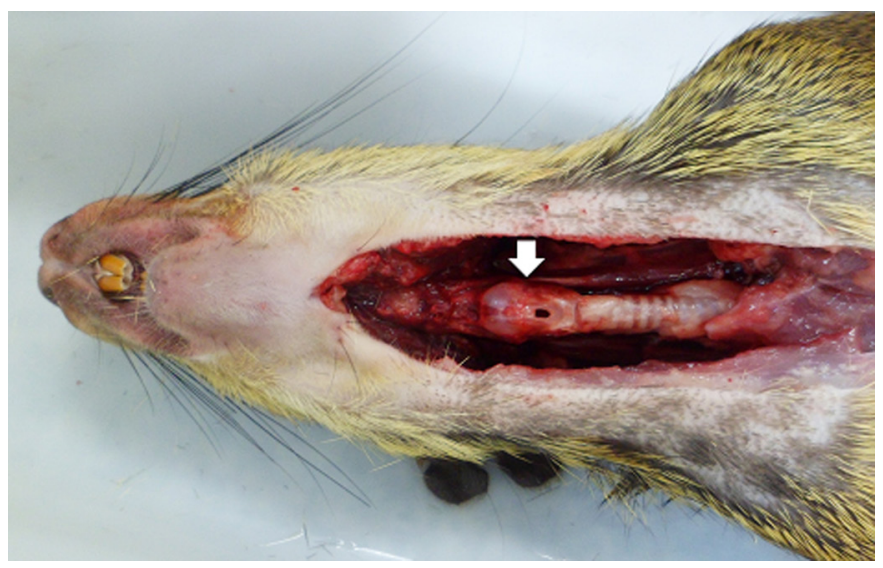

Fig.1. Região cérvicotorácica da cutia (Dasyprocta sp.) onde se observa a topografia da laringe da cutia em aspecto dorsal, indicada pela seta. 

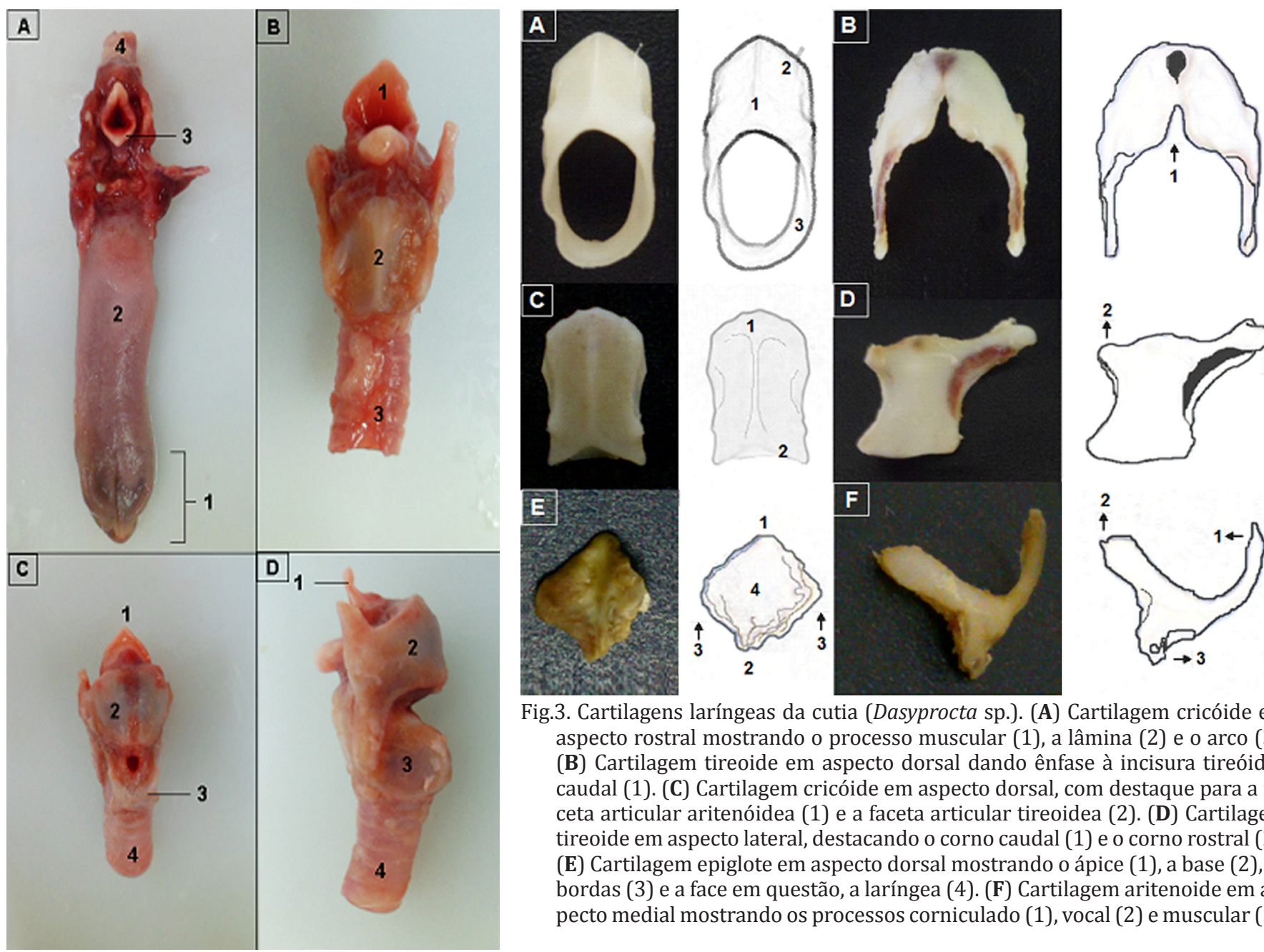

Fig.3. Cartilagens laríngeas da cutia (Dasyprocta sp.). (A) Cartilagem cricóide em aspecto rostral mostrando o processo muscular (1), a lâmina (2) e o arco (3). (B) Cartilagem tireoide em aspecto dorsal dando ênfase à incisura tireóidea caudal (1). (C) Cartilagem cricóide em aspecto dorsal, com destaque para a faceta articular aritenóidea (1) e a faceta articular tireoidea (2). (D) Cartilagem tireoide em aspecto lateral, destacando o corno caudal (1) e o corno rostral (2). (E) Cartilagem epiglote em aspecto dorsal mostrando o ápice (1), a base (2), as bordas (3) e a face em questão, a laríngea (4). (F) Cartilagem aritenoide em aspecto medial mostrando os processos corniculado (1), vocal (2) e muscular (3).
Fig.2. Laringe da cutia (Dasyprocta sp.). (A) Posição da laringe e da língua em aspecto rostral, mostrando a porção da língua que se encontra na cavidade oral (1), a porção que se encontra na região cervical (2), a cartilagem epiglote (3) com destaque para a abertura da laringe e a traquéia (4). (B) Laringe vista em aspecto dorsal, mostrando a cartilagem epiglote (1), a cricóide (2) e a traquéia (4). (C) Laringe em aspecto ventral, mostrando o ápice da cartilagem epiglote (1), a cartilagem tireóide (2), a cartilagem cricóide (3) e a traquéia (4). (D) Laringe em aspecto lateral direito, mostrando a cartilagem epiglote (1), a cartilagem tireóide (2), a cartilagem cricóide (3) e a traquéia (4).

tera, denominada lâmina. Possui uma estreita porção ventral, o arco, cuja largura modifica-se conforme a espécie em estudo (Fig.3A).A face dorsal da lâmina da cartilagem cricóide inclina-se obliquamente no sentido dorsoventral e apresenta uma crista mediana, o processo muscular, o qual é cercado por duas depressões rasas (Fig.3C). Em cada lado da borda rostral da lâmina há uma pequena faceta convexa oval para articulação com a cartilagem aritenóide do lado correspondente. Em cada uma das bordas laterais da lâmina, no sentido da borda caudal da cartilagem, há uma pequena faceta convexa para articulação com o corno caudal da cartilagem tireoide.

A cartilagem tireóide da cutia consiste de duas placas quadriláteras, direita e esquerda, que são fundidas ventralmente formando o corpo da cartilagem tireoide. As lâminas possuem formato de placas aproximadamente retangulares. 0 ângulo rostrodorsal da cartilagem tireóide de cutias se estende para formar um corno rostral curto e reto. 0 ângulo caudodorsal forma um longo e reto corno caudal, o qual medialmente apresenta uma pequena faceta para articulação com a face articular tireóidea da cartilagem cricóide (Fig.3D). Uma característica marcante dessa cartilagem em cutias é a presença de uma incisura caudal na borda caudal (Fig.3B).

A cartilagem epiglote das cutias (Dasyprocta sp.) apresenta um ápice, duas faces (lingual e laríngea), duas bordas e uma base bastante espaçada (Fig.3E). A face lingual é côncava no seu comprimento, e convexa, de lado para lado. A face laríngea tem conformação oposta. A borda caudal apresenta uma estreita extensão, o pecíolo.

As cartilagens aritenóides, em par, situam-se rostralmente à lâmina da cartilagem cricóide e são flanqueadas pelas partes dorsais das lâminas da cartilagem tireoide em cutias. Nas mesmas, são de formato irregular, mas assemelham-se a uma pirâmide de três lados, com o ápice situado rostralmente e a base caudalmente. A face dorsal côncava da cartilagem aritenóide de cutias está separada da face lateral por uma crista proeminente, na qual sua porção caudal forma o processo muscular. A face medial é achatada, a borda ventral é côncava, e esta forma um ângulo com a base 
conhecido como processo vocal. Há ainda um processo corniculado proeminente e afilando (Fig.3F).

A constituição histológica da laringe da cutia apresenta epitélio diversificado, dependendo da região, em estratificado pavimentoso queratinizado, não queratinizado e pseudoestratificado ciliado com células caliciformes.

Histologicamente observa-se que a cartilagem cricóide da laringe da cutias é constituída por cartilagem do tipo hialina. No centro do arco desta cartilagem, nota-se a presença de processo de ossificação endocondral, e pericôndrio bem delimitado dando sustentação a fibras musculares estriadas esqueléticas (Fig.4A).

A cartilagem tireóide da cutia é do tipo hialina (Fig.4B). É revestida internamente por uma mucosa do tipo respiratória, com epitélio pseudoestratificado ciliado com células caliciformes, sustentado por uma submucosa de tecido conjuntivo frouxo, seguido de uma segunda camada de tecido conjuntivo denso que se continua com o pericôndrio da cartilagem (Fig.5A).

Na cutia a epiglote mostra-se constituída de cartilagem do tipo elástica (Fig.4C). Apresentou revestimento em sua face ventral, de mucosa com epitélio estratificado pavimen- toso queratinizado e, na face dorsal, de epitélio estratificado pavimentoso não queratinizado (Fig.5B,C).

As cartilagens aritenóides de cutias do gênero Dasyprocta são do tipo hialina, no entanto, seus processos corniculados são constituídos de cartilagem elástica (Fig.4D). A mucosa que reveste esta cartilagem mostrou ser formada de epitélio estratificado pavimentoso não queratinizado, porém na região dos processos corniculados este epitélio revelou presença de queratina na sua constituição. A submucosa é constituída por tecido conjuntivo frouxo, contendo glândulas mucosas, serosas e mistas (Fig.4D).

\section{DISCUSSÃO}

A característica topográfica descrita em cutias se repete em roedores domésticos (ratos e camundongos), em quatis, animais domésticos como equinos, ruminantes, canídeos, felinos e suínos; e alguns animais de cerrado: cachorro-do-mato, lobo-guará, raposa-do-campo e macaco-prego (Araujo 2010, Leonel et al. 2012, Oliveira et al. 2012).

Comparado com a cartilagem cricóide de cutias, o processo muscular é bem demarcado no bovino (Sisson \& Grosman 1986). A medida da largura do arco é inferior no

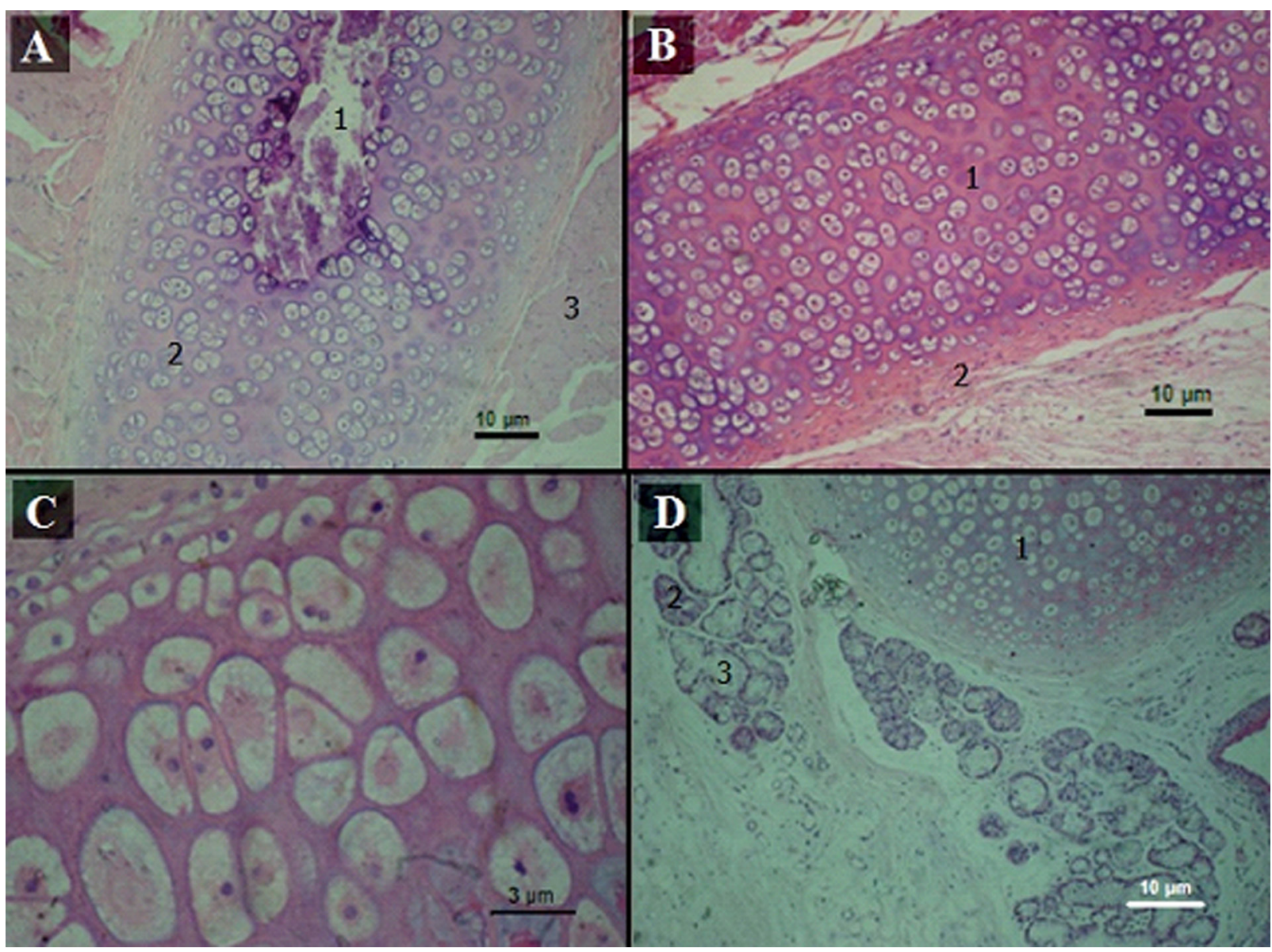

Fig.4. Cartilagens laríngeas da cutia (Dasyprocta sp.). (A) Cartilagem cricóide mostrando ossificação endocondral do arco da cartilagem (1), a cartilagem hialina (2) e o músculo estriado esquelético (3) corados pelo método de HE e visualizados em objetiva de10x. (B) Cartilagem tireoide mostrando a cartilagem hialina (1) e o pericôndrio (2) corados pelo método de HE e visualizados em objetiva de 10x. (C) Cartilagem epiglote mostrando condrócitos banhados em uma matriz cartilagínearica em fibras elásticas, caracterizando a cartilagemelástica. HE, obj.40x). (D) Cartilagem aritenóide mostrando a cartilagem hialina (1), glândula serosa (2), glândula mucosa (3), HE, obj.10x. 


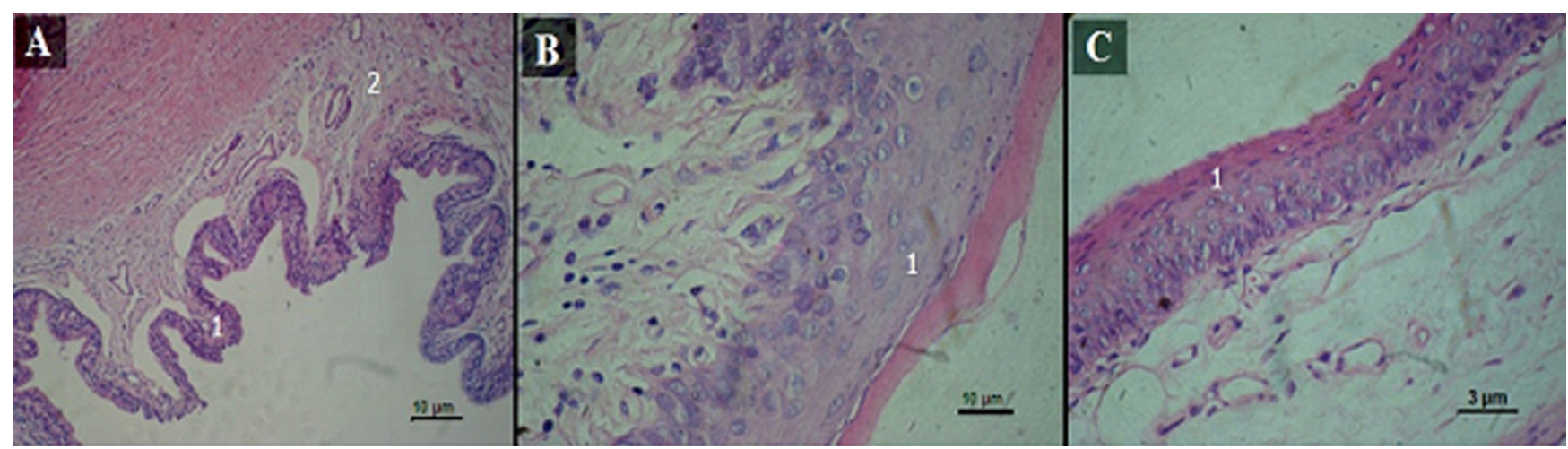

Fig.5. Cartilagens laríngeas da cutia (Dasyprocta sp.). (A) Mucosa da cartilagem tireóide da cutia mostrando seu epitélio respiratório e epitélio pseudo-estratificado ciliado com células caliciformes (1) e submucosa de tecido conjuntivo frouxo (2). HE, obj.10x. (B) Corte histológico da face ventral da epiglote mostrando a mucosa com epitélio estratificado pavimentoso queratinizado (1). HE, obj.40x. (C) Corte histológico da face dorsal da epiglote mostrando a mucosa com epitélio estratificado pavimentoso não queratinizado (1). HE, obj.40x.

quati, por exemplo, e superior em ruminantes e equinos, tendo em ratos e camundongos a largura semelhante $(\mathrm{Bu}-$ dras \& Habel 2003, Araujo 2010, Oliveira et al. 2012).

Em equinos, ruminantes e felinos o arco da cartilagem cricóide mostrou ser menos estreito quando comparado com caninos. No cachorro-do-mato (Cerdocyon thous) foi visualizado um processo muscular bastante espesso, ao contrário da raposa-do-campo (Pseudalopex vetulus), na qual a mesma estrutura apresentou aspecto afilado (Adaro et al. 2004, Vaz et al. 2005, Corgozinho et al. 2008, Leonel et al. 2012, Oliveira et al. 2012).

Nos quatis (Nasua nasua) e nos equinos, a cartilagem tireoide compreende a maior dentre todas as cartilagens, porém em cutias mostrou-se de tamanho pouco significativo frente à cartilagem cricóide. Além disso, a proeminência laríngea no bovino é mais demarcada do que nas cutias. Lateralmente, o corno rostral presente na cartilagem das cutias é longo e reto no gato, de formato afilado no cão e está ausente em suínos, sendo que o corno caudal neste último é curto e largo. A incisura tireóidea caudal encontrada nas cutias é em formato de ' $\mathrm{U}$ '; no lobo-guará (Chrysocyon brachyurus) apresentou um formato de ' $\mathrm{V}$ ' (Sisson \& Grosman 1986, Budras \& Habel 2003, Wysocki 2008, Leonel et al. 2012, Oliveira et al. 2012).

A cartilagem epiglote apresentou ápice pontiagudo e presença de pecíolo no cão e equino; ausência de pecíolo no gato e bordas dobradas no sentido dorsal e medial no suíno. No macaco-prego (Cerdocyon thous) apresentou uma bifurcação no seu ápice, ao invés de um aspecto pontiagudo observado nos outros animais analisados (Sisson \& Grosman 1986, Leonel et al. 2012).

0 ápice da cartilagem aritenóide dos quatis, ratos, equinos, suínos, felinos, caninos e bovinos possui fusionado a ele uma cartilagem corniculada que se projeta dorsalmente (Sisson \& Grosman 1986, Budras \& Habel 2003, Adaro et al. 2004, Vaz et al. 2005, Duarte et al. 2006, Corgozinho et al. 2008, Araujo et al. 2010, Cook 2012, Oliveira et al. 2012). A cartilagem aritenóide é consideravelmente irregular em animais silvestres e espécies domésticas. Nos quatis, por exemplo, o processo corniculado forma a margem caudal da entrada da laringe (Oliveira et al. 2012). Nos felinos, por apresentarem o ápice pouco desenvolvido, não possuem o processo corniculado, conforme Cook (2008). Existe ainda a cartilagem cuneiforme, ausente em bovinos e felinos, estando presente apenas em equinos, caninos e em alguns silvestres como o macaco-prego (Cerdocyon thous), o lobo-guará (Chrysocyon brachyurus), o cachorro-do-mato (Cerdocyon thous) e a raposa-do-campo (Pseudalopex vetulus) (Sisson \& Grosman 1986, Budras \& Habel 2003, Vaz et al. 2005, Corgozinho et al. 2008, Leonel et al. 2012).

Concordando com Duarte (2006), ratos e camundongos também estão submetidos à esta mesma descrição histológica. Porém, quatis e outros animais silvestres de mesma ordem não apresentam epitélio pseudoestratificado ciliado nas cartilagens da laringe (Oliveira et al. 2012).

Assim, na constituição da cartilagem cricóide, quatis, animais domésticos e alguns animais silvestres apresentam cartilagem hialina similar em cutias (Banks 1992, Silva 2010, Oliveira et al. 2012). Na cartilagem tireóide do quati (Nasua nasua), não há um epitélio detido de cílios, ou seja, um epitélio respiratório. Estudos a respeito mostraram apenas que há cartilagem hialina no segmento tireóideo (Oliveira et al. 2012).

As características da cartilagem epiglote da cutia não podem ser direcionadas para alguns roedores domésticos. A porção ventral da cartilagem epiglote de ratos e camundongos está revestida por um epitélio pseudoestratificado ciliado, e a porção dorsal por um epitélio estratificado escamoso (Duarte et al. 2006, Ibe et al. 2011). A cartilagem epiglote é do tipo elástica em todos os animais descritos. 0 epitélio de carnívoros, suínos e ruminantes apresentou corpúsculos gustativos (Banks 1992). Nos quatis, mostrou ser do tipo pavimentoso estratificado não queratinizado com presença de glândulas mistas. Na aritenóide, o epitélio desses animais na porção dorsal é estratificado pavimentoso queratinizado e na ventral é não queratinizado. (Oliveira et al. 2012).

Os ratos utilizados nas pesquisas de Duarte et al. (2006) apresentaram, próximo à inserção da cartilagem aritenóide na laringe, a transição do epitélio escamoso para epitélio respiratório, sendo este o local mais sensível às alterações celulares consequentes da exposição do órgão à produtos químicos (Duarte et al. 2006, Araujo 2010). 


\section{CONCLUSÕES}

A laringe da cutia (Dasyprosta sp.) apresentou as cartilagens: cricóide, tireoide, epiglote, aritenóide e seu processo corniculado, não possuindo a cartilagem cuneiforme. Uma das características marcantes na espécie em estudo é a presença da incisura tireóidea caudal na cartilagem tireoide.

A laringe da cutia mostrou apresentar restrições ligadas à clinica pela sua localização caudal na região cervical, explicada pelo comprimento da língua que invade esta região deixando uma pequena porção da mesma na cavidade oral.

0 epitélio da cutia varia, dependendo da região, em estratificado pavimentoso queratinizado, não queratinizado e pseudo-estratificados ciliado com células caliciformes.

0 presente trabalho esclarece informações a respeito da laringe da cutia capaz de servir como base nas práticas relacionadas à clinica de silvestres, contribuindo com estudos descritivos envolvendo cutias e outros roedores.

Agradecimentos.- À Universidade Federal do Piauí , à Fundação de Amparo à Pesquisa do Estado do Piauí (FAPEPI) e ao CNPq.

\section{REFERÊNCIAS}

Adaro L.A., Rico B., Flores E. \& Cattaneo G. 2004. Laringe canina y humana: un estudio para establecer homología. Arq. Ciênc. Vet. Zool. 2(7):135-139.

Araújo S.A.C. 2010. Anestesia em roedores. Dissertação de Mestrado Integrado em Medicina Veterinária, Instituto de Ciências Biomédicas Abel Salazar, Universidade de Porto, Porto, Portugal. 37p.

Arruda M. \& Julião J. 2006. 0 papel ecológico da cutia: um mamífero roedor encontrado em áreas urbanas. Disponível em <www.tvcultura.com. br/reportereco> Acesso em 13 jul. 2012.

Banks W.J. 1991. Histologia Veterinária Aplicada. 5ํㅗ ed. Manole, São Paulo, SP. 502p.

Budras K.D., Habel R.E., Wunshe A. \& Buda S. 2003. Bovine Anatomy. $5^{\text {th }}$ ed. Schlütersche GmbH, Hannover. 138p.

Cook W.R. 2008. Observations on the upper respiratory tract of the dog and cat. J. Small Anim. Pract. 5:309-329.

Corgozinho K.B., Souza H.J.M., Ferreira A.M.R., Cunha S.C. \& Damico C. 2008. Dispnéia provocada por tumor laringeano em gatos no período de 1997 a 2007. Acta Scient. Vet. 3(36):289-292.

Cunsolo E.M. 2010. Anatomy and physiology of the operated larynx. Acta Otorhinolaryngol. Ital. 30(5):238-243.

Diniz B.L.M. 2007. Máscara laríngea como alternativa à sonda endotraqueal em cutias (Dasyprocta prymnolopha), anestesiadas sob respiração espontânea ou controlada. Dissertação de Mestrado em Ciência Animal, Universidade Federal do Piauí, Teresina, PI. 84p.

Duarte J.L., Faria F.A.C., Ceolin D.S., Cestari T.M. \& Assis G.F. 2010. Efeitos da inalação passiva da fumaça de cigarro sobre as pregas vocais de ratos. Revta Bras. Otorrinolaringol. 2(72):210-216.

Hosken F.M. 2001. Criação de cutias. Aprenda Facil, Viçosa, MG. 234p.

Ibe C.S., Onyeanusi B.I., Salami S.O. \& Nzalak J.O. 2011. Microscopic anatomy of the lower respiratory system of the African giant pouched rat ( $\mathrm{Cri}$ cetomys gambianus Waterhouse, 1840). Int. J. Morphol.. 1(29):27-33.

Junior C.H.L.S. 2008. Principais doenças respiratórias que acometem psitacídeos e passeriformes criados como animais de estimação. Tese do Curso de Clínica Médica e Cirúrgica de Animais Selvagens e Exóticos. Universidade Castelo Branco. Rio de Janeiro, RJ. 98p.

Leonel L.C.P.C., Lima T.C., Carvalho-Barros R.A., Silva T.A.M., Silva A.P.A., Ribeiro L.A. \& Silva Z. 2012. Anatomia descritiva comparativa das cartilagens da laringe de mamíferos do cerrado com o homem e animais domésticos. Anais V Congresso Brasileiro de Anatomia, Salvador, BA, p.24. (Resumo)

Marques A.A.B. 2002. Lista de Referência da Fauna Ameaçada de Extinção no Rio Grande do Sul. Decreto no. 41.672, de 11 junho de 2002. FZB/ MCT-PUCRS/PANGEA, Porto Alegre, RS. 52p.

Martins L.L., Oliveira F.S., Toniollo G.H., RodriguesV., Pauloni A.P. \& Machado M.R.F. 2010. Anestesia epidural em cutias (Dasyprocta azarae) submetidas à ovariossalpingohisterectomia. Biotemas 2(23):177-181.

Oliveira V.C., Souza A.F., Santos A.C., Bertassoli B.M., Rosa R.A., Carvalho A.F., Martins J.F.P. \& Mançanares C.A.F. 2012. Estudo morfológico do sistema respiratório de quati (Nasua nasua). Biotemas 1(25):81-92.

Philippi F.F. 2005. Anatomia das Pregas Vocais e Fisiologia da Fonação: fonoatividade. Faculdade de Medicina da Universidade de São Paulo, São Paulo, SP. 21p.

Pires A.S. \& Galetti M. 2012. The agouti Dasyprocta leporina (Rodentia: Dasyproctidae) as seed dispenser of the palm Astrocaryumaculeatissimum. Mastozool. Neotrop. 1(19):147-153.

Silva M.S.S. 2010. Rastreio de parasitas gastrintestinais, pulmonares, cutâneos e musculares em canídeos domésticos e silvestres no norte de Portugal. Dissertação de Mestrado em Medicina Veterinária, Faculdade de Medicina Veterinária, Universidade Técnica de Lisboa, Lisboa, Portugal. 131p.

Sisson S., Grossman J.D. \& Getty R. 1986. Anatomia dos Animais Domésticos. 5ㄹ ed. Guanabara Koogan, Rio de Janeiro, RJ. 878p.

Stolf A.M. 2007. Relatório de Estágio supervisionado áreas: Medicina de Animais Selvagens, Cirurgia de Pequenos Animais. Universidade Federal do Paraná, Curitiba, PR. 52p.

Vaz B.B.,Thomassian A., Nicoletti J.L.M., Hussni C.A., Alves A.L.G. \& Figueiredo L.M.A. 2005. Aspectos histológicos de laringes de equinos submetidos à aritenoidectomia subtotal com e sem remoção do revestimento mucoso. Vet. Notícias 2(11):23-29. 